\title{
PERSONNEL PROTECTION IN THE USE OF RADIOACTIVE ISOTOPES
}

\author{
BY G. FAILLA
}

\section{(From the College of Physicians and Surgeons, Columbia University, New York City)}

Artificially produced radioactive isotopes are distributed by the Atomic Energy Commission according to strict rules on account of the dangers inherent in the handling of such materials. Before an individual can obtain radioisotopes, he has to present evidence that he possesses the knowledge, facilities and equipment to meet the minimum standards of safe handling. The Isotopes Division in Oak Ridge, Tennessee, is anxious to help the users in matters of protection and makes available to them articles or pamphlets on this subject, as well as expert advice. It may be assumed, therefore, that the reader is familiar with recent publications on the subject or may get the available information by simply asking for it. Also, a comprehensive report on "Safe Handling of Radioactive Isotopes and Fission Products" is being prepared by the National Committee on Radiation Protection, and will soon be ready for distribution. Accordingly, in the present article no attempt will be made to cover the whole subject, and in fact only a few topics will be discussed, which in the opinion of the writer deserve special emphasis.

The mental attitude of the worker plays an extremely important part in the problem of protection. Most people who have received some cursory instruction, are very careful at the start. Sooner or later a minor "emergency" arises and the individual decides that it is necessary to disregard some rules. The "emergency" might consist simply in not having allowed enough time for the preparation of a sample to be used on a patient at a specified time. Perhaps the surgeon is waiting for the material in the operating room. To save time, the worker then goes through the necessary manipulations without using the protection devices provided for the purpose. For some time thereafter, he might be a little apprehensive and think that perhaps he got too large an exposure. However, unless the exposure was really excessive, he cannot detect any ill effects from it and after a few such experiences he is apt to conclude that the danger of overexposure has been exaggerated, or that perhaps he is particularly resistant to radiation.

Every worker must be made to realize that radiation injury may not become apparent or serious for many years. This is true even in the case of a single exposure or a few exposures taking place within a matter of weeks. Recently the writer heard of a case in England in which cancer of the skin developed 40 years after the patient had been treated with X-rays in the same region for another ailment. In numerous radiologists, and technicians, cancer of the skin of the hands has developed 15 to 25 years after they started to work with X-rays or radium, although the bulk of the exposure occurred during the first few years when the danger of radiation was not fully realized. The individual worker simply has no way of telling what constitutes a safe exposure from his own experience. By the time that some tissue damage becomes evident to him, it may be too late to do anything about it and eventually serious injury or death may result. Therefore, each worker should accept the permissible limits of exposure set by competent authorities and should strive by all possible means to keep his exposure well below these limits at all times.

In this connection it is well to point out that no matter how careful an individual may be, an occasional overexposure is apt to occur through some accident or through carelessness on somebody else's part. If the person has maintained his exposure well below permissible limits, he is in a better position to escape injury if such overexposures do occur through circumstances beyond his control. Furthermore, the worker should never exceed the permissible limits of exposure on the ground that after some definite date he will no longer work with radiation. Conditions may change and he may decide to continue working with radiation indefinitely. It is not good judgment to acquire a handicap needlessly.

People with considerable knowledge of the subject sometimes get in trouble by attempting to estimate the dosage rate in a region in which they are 
anxious to work, on the spur of the moment and under great mental stress. It should be an inalterable rule never to venture into a potentially dangerous region without first surveying it with the proper kind of measuring instrument known by actual test to be in good working order. A region in which there is a source of ionizing radiation must be considered to be potentially dangerous, whether protective measures have been taken or not, until proven safe by proper measurements. In other words the worker must not decide that the protective measures are satisfactory by mere inspection, unless he is an expert in the field of protection.

In this connection, some common pitfalls will be mentioned. Lead bricks are usually available in a radioactivity laboratory. With these, temporary protective barriers are built up. Sometimes a single barrier is placed between the source and the part of the room that it is desired to protect. This may or may not be sufficient depending on the strength of the source and the radiation it emits. The lead thickness may be ample for radiation passing through it but radiation emitted in other directions will strike walls, etc., and will be scattered all over the room. More often the container rests on the table and lead bricks are placed around it. Again radiation emitted in the direction of the floor and towards the ceiling can be scattered throughout the room. It is always best to surround a gamma ray source with lead of sufficient thickness in all directions. When temporary barriers are set up, a radiation survey with an appropriate meter should be made to make sure that the dosage rate at all points of the working space is within permissible limits. Adjoining rooms should be surveyed too.

In making a survey for scattered radiation in the case of a source not completely surrounded by lead, it should be remembered that the dosage rate may be highest in regions located at considerable distances from the source. Thus all occupied space in the vicinity of a strong source should be surveyed. Ordinary survey instruments do not respond equally to radiation reaching them from different directions. Hence at any one point it is necessary to take readings with the instrument pointed in different directions to determine the maximum and to establish the cause in case additional protection is needed. It should be remem- bered that floors and ceilings, as well as the walls, scatter radiation, and the instrument should be pointed downward and upward, too.

The preceding discussion is specifically applicable to gamma ray sources. In the case of materials emitting high energy beta rays (e.g., $\mathrm{P}^{32}$ ) scattered radiations must also be taken into account. In fact the danger of scattered beta radiation is more insidious because it is often unsuspected. Marked scattering of beta rays occurs in air, so the presence of solid bodies in the neighborhood of the source is not necessary to scatter beta rays into a region that might be assumed to be well protected. For example the beam of beta rays emerging through the mouth of an uncapped bottle containing a $\mathrm{P}^{\mathbf{3 2}}$ solution, is scattered far beyond its geometric confines. In fact some beta rays from the beam will reach practically every part of a small room. The dosage rate at any one point will depend on the amount of $\mathrm{P}^{32}$ in the bottle, and on other obvious factors. In making a radiation survey in this case it is imperative to point the instrument in different directions because usually beta rays can enter the device only through one side, which is provided with a suitable window.

When large amounts of beta ray emitting material are involved, it may be necessary to provide protection against the X-rays ("bremsstrahlen"), produced by the beta rays in the material itself and in the container. The production of these rays is the same as that of $\mathrm{X}$-rays in an $\mathrm{X}$-ray tube, when the electrons impinge on the target. As is well known the higher the atomic number of the target material, the higher the X-ray output. Similarly, $\mathrm{P}^{32}$ in a lead container would produce a much higher intensity of $\mathrm{X}$-rays than when placed in a glass bottle. Therefore, in the case of pure beta ray sources, shielding is best accomplished by the use of low atomic number materials. (This is the opposite of gamma ray shielding.)

It is generally assumed that isotopes emitting gamma rays are more dangerous to handle than pure beta emitters (from the point of view of external irradiation). This is obviously true because, for one thing, there is usually beta radiation of not negligible energy associated with the gamma rays. The main reason, however, is that in general the penetrating power of gamma rays is much greater than that of beta rays. Thus only 
the superficial tissues of the body (to a depth of at most several millimeters) are irradiated by beta rays, whereas the entire body is traversed by gamma rays. In the case of external sources, eventual production of cancer of the skin and induction of leukemia constitute the principal hazards of exposure to ionizing radiation. With gamma rays both hazards are potentially present, whereas with beta rays (which do not penetrate to the blood forming organs) only cancer of the skin need be considered. Since leukemia is always fatal but cancer of the skin can be cured in a large percentage of cases, it is obvious that exposure to gamma rays is by far the more dangerous. However, this statement, which is true in general, must not be interpreted to mean that there is little danger involved in the handling of beta ray isotopes.

At the present time most university or hospital laboratories handle rather small quantities of radioactive isotopes. Reasonable care is exercised in storing these materials. Therefore, most of the exposure occurs in carrying out some manipulative procedure at close range with rather crude protective devices. Under such conditions the hands are exposed to much higher intensities of radiation than the rest of the body and the principal hazard is tissue damage in the hands that may lead to cancer of the skin later-no matter what kind of radiation is emitted by the material. In this respect and under existing conditions, therefore, the external irradiation hazard is not so different in the two cases (e.g., unshielded equal amounts of $\mathrm{P}^{32}$ and $\mathrm{I}^{131}$ ) as might be supposed. Hence the importance of handling $\mathrm{P}^{32}$ with great care also. There is an additional reason for doing so. Most workers handle more than one isotope and the total exposure of the hands from all sources must be considered. In the case of beta ray isotopes it is relatively simple to provide, or even improvise, handling devices that reduce the exposure of the hands to a low level, because the radiation can be completely stopped by light shields. It is, therefore, advantageous to do so, since then exposure to gamma rays (for which adequate protection is more difficult to provide) can be correspondingly greater.

The importance of taking great precautions in the handling of beta ray sources can be brought out best by numerical examples. The data given in
TABLE I

Dosage rates at different perpendicular distances from the surfaces of two radioactive preparations

\begin{tabular}{|c|c|c|c|}
\hline $\begin{array}{l}\text { Distance } \\
\text { from } \\
\text { surface }\end{array}$ & $\begin{array}{l}10 \text { mc Pss } \\
80 l u t i o n \\
\text { in } 10 \mathrm{~cm} \\
\text { dish } \\
\text { (see text) }\end{array}$ & $\begin{array}{l}10 \mathrm{mg} \text { Ra tube } \\
\text { applicator } \\
\text { (gamma rays } \\
\text { only) } \\
\text { (see text) }\end{array}$ & $\begin{array}{l}\text { Ratio } \\
\text { Paz/Ra }\end{array}$ \\
\hline $\begin{array}{r}c m \\
0 \\
1 \\
2 \\
5 \\
10 \\
25 \\
50 \\
100\end{array}$ & $\begin{array}{l}\text { e.r./hr } \\
740 \\
300 \\
112 \\
31.1 \\
9.94 \\
1.80 \\
0.43 \\
0.084\end{array}$ & \begin{tabular}{l}
\multicolumn{1}{r}{$r / h r$} \\
450 \\
41.6 \\
14.4 \\
2.77 \\
0.785 \\
0.131 \\
0.033 \\
0.0083
\end{tabular} & $\begin{array}{l}1.65 \\
7.2 \\
7.8 \\
11.2 \\
12.7 \\
13.8 \\
13.0 \\
10.1\end{array}$ \\
\hline
\end{tabular}

Table I will serve this purpose well in that comparison can be made with the more familiar problem of radium protection. First it is necessary to explain briefly how the data were obtained. ${ }^{1}$ The dosage rate at the surface of the $\mathrm{P}^{32}$ solution (740 e.r. $/ \mathrm{hr}^{2}$ ) was determined by means of an extrapolation ionization chamber in which one electrode was the solution itself. By subsidiary experiments, a correction factor was determined to reduce the readings to what they would have been, had both electrodes been made of water. (The amount of phosphate in the $\mathrm{P}^{32}$ solution was entirely negligible.) The results are expressed in terms of the number of ion pairs produced per gram of air divided by the number of ion pairs corresponding to one roentgen, that is, $1.62 \times$ $10^{12}$ per gram of air. This then is the e.r. as used here.

It should be noted that 740 e.r./hr is the dosage rate at the surface of the solution when it is in contact with the body (e.g., the hand or even a finger),

1 Details of the experiments and additional data will be published in the near future by the writer and $\mathrm{Mr}$. Norman Baily.

2 In the absence of an internationally accepted unit of quantity of radiation applicable to all types of ionizing radiations, different authors have defined units such as the "equivalent roentgen" (e.r.), the "roentgen equivalent physical" (rep), etc., for dosage purposes. There is some confusion at present as to the definitions and magnitudes of these units, because different effects have been used to establish the "equivalence" with the roentgen. Sometimes the equivalence is based on the number of ion pairs produced per gram of air, at other times on the energy absorbed per gram of air or per gram of tissue. The difference in magnitude of these units is roughly $10-15 \%$, depending on which ones are compared. The meaning of the e.r. as used here is explained in the text. 
because the contribution of back-scattered beta rays was purposely included in the measurements. The dosage rates at different distances from the $\mathrm{P}^{32}$ source were measured with an extrapolation chamber in which the front electrode (graphited nylon film) had an equivalent thickness of $1.5 \mathrm{mg} /$ $\mathrm{cm}^{2}$. The back electrode of thick polystyrene provided essentially the same back scattering as soft tissue. Accordingly, the figures represent the dosage rates that would obtain at the surface of the skin at the different distances from the $\mathrm{P}^{\mathbf{3 2}}$ source. In the case of the radium tube the dosage rate at the surface was determined by measurement with a cylindrical extrapolation chamber (1). The other values were calculated and do not include back scattering, which, however, is negligible for short distances.

The dosage rates given in the table are for the following sources: (1) Platinum tube containing $10 \mathrm{mg}$ (10 mc) of radium, with a wall thickness of $0.5 \mathrm{~mm}$ and an active length of $12-14 \mathrm{~mm}$, enclosed in a plastic sleeve having an outside diameter of $6.34 \mathrm{~mm}$ ( $1 / 4$ inch). (2) "Thick" source consisting of $10 \mathrm{mc}$ of $\mathrm{P}^{32}$ in water solution in a polystyrene dish with an area of $10 \mathrm{~cm}^{2}$ and a depth of $1 \mathrm{~cm}$ (10 cc).

It is evident at a glance that the dosage rates for both sources are very high at short distances. A finger in contact with the surface of the $\mathrm{P}^{32}$ solution would receive 740 e.r. in one hour, 12.3 e.r. in one minute, or 0.205 e.r. in one second. A finger in contact with the radium applicator would receive about two-thirds of this dose in the same time. In comparing the values for the $\mathrm{P}^{32}$ solution and the radium applicator, the most striking thing is that the dosage rate produced by the former shows a marked increase relative to the radium applicator dosage rate, as the distance increases to 25 and even $50 \mathrm{~cm}$. At a distance of $1 \mathrm{~cm}$ it is already 7.2 times greater than that of the radium tube and at $25 \mathrm{~cm}$ it is 13.8 times greater. This means that at a distance of $25 \mathrm{~cm}$ directly over the $10 \mathrm{mc} \mathrm{P}^{82}$ solution, the surface of the hand would receive, in a given time, the same amount of radiation that $138 \mathrm{mg}$ of filtered radium would deliver at the same distance and in the same time. In other words, at this distance and insofar as the surface of the skin is concerned, the $10 \mathrm{mc}$ $\mathrm{P}^{32}$ solution is "equivalent" to $138 \mathrm{mg}$ of filtered radium. At $100 \mathrm{~cm}$ distance it is equivalent to 101 mg of filtered radium. This shows clearly that distance is less effective in decreasing the dosage rate of high energy beta ray sources than in the case of penetrating gamma rays. It will be seen further that the dosage rate is quite high even at a distance of $100 \mathrm{~cm}$ from $10 \mathrm{mc}$ of $\mathrm{P}^{32}$ as a thick source-in which case most of the radiation is absorbed within the source itself. If the same amount of $\mathrm{P}^{32}$ had been evaporated to dryness in the same dish, the dosage rates for all distances would have been much higher. ${ }^{8}$ Therefore it is more dangerous to handle $\mathrm{P}^{32}$ as a thin dry film or deposit than as a thick source of dimensions comparable to the maximum range of the beta rays. It should be noted in this connection that radium in the form of a pure salt or in solution is very dangerous (more so than $\mathrm{P}^{32}$ ), because of the large amount of high energy beta radiation which it liberates in addition to the gamma rays." The comparison is made here with sources such as are commonly used in radiological practice.

It is important at this point to reiterate that the dosage rates given in Table I relate only to the surface of the skin. They are directly applicable to the problem of protecting the skin but they give an exaggerated picture of the radiation hazard as a whole. The comparison with the gamma ray dosage rates of the radium applicator is particularly misleading in this respect. It was made in order to emphasize the importance of protection in the handling of $\mathrm{P}^{32}$ in hospital laboratories where familiarity with the handling of filtered radium might well lead to overexposure of the hands. One who has handled radium applicators for years might not realize that the skin of the hand would get very much more radiation from $\mathrm{P}^{32}$ sources of equal millicurie content. However, the overall danger is much greater in the case of radium because the gamma rays penetrate the whole body and can cause damage, with much more serious possible complications (leukemia). The most energetic beta rays of $\mathrm{P}^{32}$ are completely absorbed in $8 \mathrm{~mm}$ of tissue, and $2 \mathrm{~mm}$ of tissue reduce the

\footnotetext{
8 Experimental data obtained under these conditions will be published later.

4 It is well known that radium taken into the body is much more dangerous than $\mathbf{P}^{32}$. In the present discussion only the danger of irradiation by external sources is being considered.
} 
dosage rate of a thick $\mathrm{P}^{32}$ source in contact with the skin to about $10 \%$.

Mention has already been made that in making a radiation survey in a laboratory, the proper kind of instrument should be used. This is particularly true in the case of beta rays. Since the main concern is the dose received by the skin, the instrument should be capable of measuring this quantity. At present, ionization chambers are best for this purpose. Obviously the window that admits the radiation into the chamber must be very thin. ${ }^{5}$ The walls of the chamber should be made of, or lined with, organic material in order that the contribution of scattered beta rays to the ionization current be essentially the same as that of living tissue. The thickness of this material should be sufficient to provide the maximum back scatter. One-half the range of the fastest beta rays to be measured, or approximately $1 / 8$ inch, is ample. It is desirable to make the chamber small and particularly shallow so that the readings would be representative of the dosage rate at the point of reference. Unfortunately, in the usual survey meters, large chambers are used to provide currents readily measurable by portable instruments. The calibration of these meters then presents a

5 The cells at the surface of the skin to a depth of perhaps $7 \mathrm{mg} / \mathrm{cm}^{2}$ are considered to be non-reactive to reasonably large doses of radiation since they are practically "dead." A window of this thickness is satisfactory to determine the dosage rate at the depth of the presumably radiosensitive skin cells, when the ionization chamber is properly designed in other respects. major problem. As a matter of fact, no such instrument can possibly read beta ray dosage rates correctly for all isotopes, all distances, and all shapes and sizes of source. The data of Table I may be used to advantage in calibrating beta ray survey meters for $\mathrm{P}^{32}$ sources similar to that described here and at various distances. It should be noted in this connection that the area of the source influences the reading considerably. Thus, maintaining both the depth of solution $(1 \mathrm{~cm})$ and the concentration $(\mathrm{mc} / \mathrm{cc}$ ) constant, the dosage rate at distances of 10 to $100 \mathrm{~cm}$ will increase approximately in proportion to the surface area, when the area is varied from 10 to $40 \mathrm{~cm}^{2}$.

Time does not permit discussion of other topics. It may be well to state, however, that the National Committee on Radiation Protection has revised the permissible limits of exposure to ionizing radiation. The new values, of interest in the present connection, that will soon be recommended formally are: (1) For whole body exposure to $\mathrm{X}$ - or gamma rays up to three million volts, $0.3 \mathrm{r}$ per week measured in air. (2) For local exposure essentially limited to the hands only, $1.5 \mathrm{r}$ per week or 1.5 rep per week in the case of beta rays, in both cases measured at the basal layer of the epidermis, which in general may be assumed to be at a depth of $7 \mathrm{mg} / \mathrm{cm}^{2}$ below the surface of the skin.

\section{BIBLIOGRAPHY}

1. Quimby, E. H., Marinelli, L. D., and Blady, J. V. Secondary filters in radium therapy. Am. J Roentgenol. \& Radium Ther., 1939, 41, 804. 